Fixed Point Theory, 18(2017), No. 2, 523-544

DOI 10.24193/fpt-ro.2017.2.41

http://www.math.ubbcluj.ro/ ${ }_{\text {nodeacj/sfptcj.html }}$

\title{
A CONTRACTION PRINCIPLE ON GAUGE SPACES WITH GRAPHS AND APPLICATION TO INFINITE GRAPH-DIRECTED ITERATED FUNCTION SYSTEMS
}

\author{
T. DINEVARI AND M. FRIGON
}

Département de Mathématiques et de Statistique

Université de Montréal

Montréal, H3C 3J7, Canada

E-mail: frigon@dms.umontreal.ca and toktam@dms.umontreal.ca

\begin{abstract}
We consider multi-valued maps defined on a complete gauge space endowed with a directed graph. We establish a fixed point result for maps which send connected points into connected points and satisfy a generalized contraction condition. Then, we study infinite graph-directed iterated function systems ( $H$-IIFS). We give conditions insuring the existence of a unique attractor to an $H$-IIFS. Finally, we apply our fixed point result for multi-valued contractions on gauge spaces endowed with a graph to obtain more information on the attractor of an $H$-IIFS. More precisely, we construct a suitable gauge space endowed with a graph $G$ and a suitable multi-valued $G$-contraction such that its fixed points are sub-attractors of the $H$-IIFS.
\end{abstract}

Key Words and Phrases: Fixed point, multi-valued map, contraction, graph, graph-directed iterated function system, infinite system, attractor gauge space.

2010 Mathematics Subject Classification: 47H10, 47H04, 47H09, 28A80, 54E15.

\section{REFERENCES}

[1] M.F. Barnsley, Fractals Everywhere, Academic Press Inc., Boston, 1988.

[2] A. Chiş, R. Precup, Continuation theory for general contractions in gauge spaces, Fixed Point Theory Appl., 3(2004), 173-185.

[3] M. Das, Contraction ratios for graph-directed iterated constructions, Proc. Amer. Math. Soc., 134(2006), 435-442.

[4] T. Dinevari, M. Frigon, Fixed point results for multivalued contractions on a metric space with a graph, J. Math. Anal. Appl., 405(2013), 507-517.

[5] T. Dinevari, M. Frigon, Applications of multivalued contractions on graphs to graph-directed iterated function systems, Abstr. Appl. Anal., 2015 (2015), Art. ID 345856, 16 pp.

[6] G.A. Edgar, Measure, Topology, and Fractal Geometry, Springer-Verlag, New York, 1990.

[7] M. Frigon, Fixed point results for generalized contractions in gauge spaces and applications, Proc. Amer. Math. Soc., 128(2000), 2957-2965.

[8] M. Frigon, Fixed point results for multivalued contractions on gauge spaces, Set Valued Mapping with Applications in Nonlinear Analysis, Ser. Math. Anal. Appl., 4, Taylor \& Francis, London, 2002, 175-181. 
[9] M. Frigon, Fixed point and continuation results for contractions in metric and in gauge spaces, Fixed Point Theory and its Applications, Banach Center Publ., Polish Acad. Sci., Warzaw, $\mathbf{7 7}(2007), 89-114$.

[10] N. Gheorghiu, Fixed point theorems in uniform spaces, An. St. Univ. Al. I. Cuza Iaşi, 28(1982), $17-18$.

[11] G. Gwóźdź-Łukawska, J. Jachymski, IFS on a metric space with a graph structure and extensions of the Kelisky-Rivlin theorem, J. Math. Anal. Appl., 356(2009), 453-463.

[12] J.E. Hutchinson, Fractals and self-similarity, Indiana Univ. Math. J., 30(1981), 713-747.

[13] J. Jachymski, The contraction principle for mappings on a metric space with a graph, Proc. Amer. Math. Soc., 136(2008), 1359-1373.

[14] R.D. Mauldin, S.C. Williams, Hausdorff dimension in graph directed constructions, Trans. Amer. Math. Soc., 309(1988), 811-829.

[15] A. Nicolae, D. O'Regan, A. Petruşel, Fixed point theorems for singlevalued and multivalued generalized contractions in metric spaces endowed with a graph, Georgian Math. J., 18(2011), 307-327.

[16] J.J. Nieto, R.L. Pouso, R. Rodríguez-López, Fixed point theorems in ordered abstract spaces, Proc. Amer. Math. Soc., 135(2007), 2505-2517.

[17] J.J. Nieto, R. Rodríguez-López, Contractive mapping theorems in partially ordered sets and applications to ordinary differential equations, Order, 22(2005), 223-239.

[18] A. Petruşel, I. Rus, Fixed point theorems in ordered L-spaces, Proc. Amer. Math. Soc., 134(2006), 411-418.

[19] A.C.M. Ran, M.C.B. Reurings, A fixed point theorem in partially ordered sets and some applications to matrix equations, Proc. Amer. Math. Soc., 132(2004), 1435-1443.

Received: April 23, 2014; Accepted: January 23, 2016. 